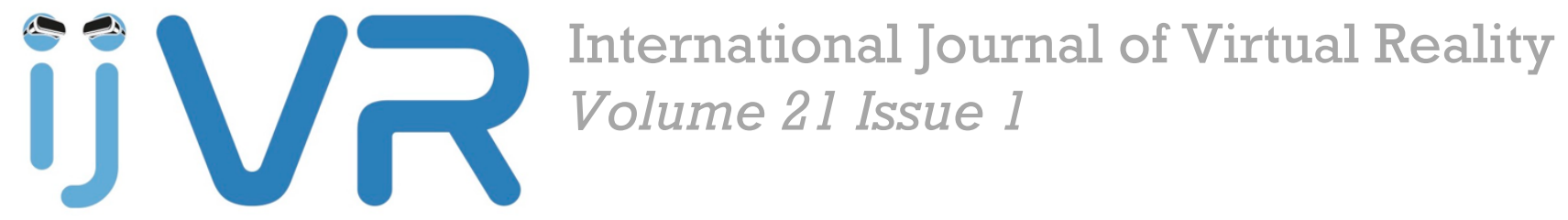

Ribeiro, N., Vigier, T., \& Prié, Y. (2021)

Tracking motor activity in Virtual Reality to reveal cognitive functioning: A preliminary study.

International Journal of Virtual Reality, 21(1), 30-46.

https://doi.org/10.20870/IJVR.2021.21.1.4782

CC BY 4.0 license

Published: 6/2021

ISSN: 2727-9979 


\title{
Tracking motor activity in Virtual Reality to reveal cognitive functioning: A preliminary study
}

\author{
Nicolas Ribeiro ${ }^{1}$, Toinon Vigier ${ }^{1}$, Yannick Prié ${ }^{1}$ \\ ${ }^{1}$ LS2N - Université de Nantes
}

Corresponding author: Yannick Prié, Yannick.prie@univ-nantes.fr

Keywords: Virtual reality; Motor system; Cognitive functioning; Flankers task

\begin{abstract}
A challenge for cognitive research is the better understanding of how motor activity influences and is influenced by other cognitive domains. We developed a preliminary study to investigate whether tracking motor functioning in virtual reality provides useful insight on cognitive functioning. We chose the flankers task as an assessment measure and built a VR environment into which seven participants completed more than 1250 trials. In addition to classical results of the flankers task showing that incongruent stimuli induce slower responses than others., we also identified how individuals are able to correct their initially incorrect motor response. This indicator may shed new light into the functioning of cognitive control in the future. We discuss the potential offered by virtual reality technology for cognitive assessment through embodied considerations of cognition.
\end{abstract}

\section{Introduction}

The ability to perform activities in everyday life depends both on motor and cognitive processes and there is a range of evidence showing that motor and cognitive functioning is intimately related (Georgopoulos, 2000; Jeannerod, 2006). For example, the action-perception brain circuits widely implicate cognition, language and communication (Pulvermüller et al., 2014) and it has been shown that action execution, observation and imagination share a largely overlapping sensory-motor system (Simos et al., 2017). Furthermore, motor and cognitive performances are both shaped by factors such as disease, age and gender (Inzitari et al., 2006; Pinheiro et al., 2013). In light of this deep relationship between motor and cognitive functioning, it is not surprising that different neurophysiological experimental research studies have shown that the motor system is a good indicator of cognitive functioning (Boyle et al., 2002; Scarmeas et al., 2005) and it could even be a greater early-predictor of cognitive decline than cognitive assessment itself (Montero-Odasso et al., 2018). More generally, as clinical neuropsychological assessments rarely use motor activity as a proxy for cognitive status, the question of how to take this into account activity to shed more light on cognitive functioning and ultimately improve these assessments emerges. The purpose of this preliminary study was to examine whether monitoring motor activity in virtual reality could provide new insight into cognitive functioning.

\subsection{Virtual reality and cognitive assessment}

The core concept of virtual reality (VR) is to immerse a subject in real time in a virtual environment. VR can be experienced through many media, but it is most widely used via head-mounted displays able to propose a visual-auditive environment, while allowing for freedom of movement (Sagnier et al., 2019). VR can create realistic environments, allowing for situations and experiments that may not be possible or secure in the physical world. VR has been used for many purposes such as medical training (Kan Yeung et al., 2021), occupational training (Sagnier et al., 2021) and education (Jensen \& Konradsen, 2018). In the last decades, VR has become more mainstream and readily available coinciding with the opening up of new possibilities in the fields of cognitive and behavioural assessment (Kan Yeung et al., 2021; Liu et al., 2019). Indeed, VR has been used in cognitive psychology to investigate and evaluate a variety of cognitive processes such as 
learning and memory (Ribeiro et al., 2021; Ribeiro et al., 2020a; Ribeiro et al., 2020b). Specifically, its usefulness for studying episodic memory is well demonstrated (La Corte et al., 2019; Plancher et al., 2012; S. A. Smith, 2019).

One of the main advantages of VR for neuropsychological assessment is the opportunity it offers to control different dimensions of what participants experience in the virtual world, such as duration, level of difficulty, pace, and timing (Kourtesis et al., 2021; Negu et al., 2016). This control also provides standardization of the setting in which the test takes place, including instructions, lighting, and item positioning. VR thus mitigates unwanted interference occurring in the real world. Another major advantage is that it allows for better recording of the participant's performance and for instance allows monitoring of the participant's motor activity. As a reminder in the present study, we investigate if this new layer of information could be useful for cognitive assessment.

The fact that neuropsychological status is usually evaluated through tasks that consist of cognitive response analysis has been described as a problem that could be resolved by adopting a more dynamic and functional approach (Gounden et al., 2017). VR can provide more detailed information about cognitive functioning by placing the patient in a setting which dynamics closely resembles the one they experience in daily life. Over the years, VR has been deemed a natural way of studying cognitive functioning. Especially (but not only) it allows clinicians to propose an everyday-like experiences that are usually absent in traditional neuropsychological testing (Parsons, 2015). We suggest that the opportunity to evaluate motor activity in VR settings could facilitate the assessment of cognitive functioning in psychological testing.

\subsection{Motor and cognitive functioning are densely intertwined}

The idea that motor and cognitive functions are tightly knit is not new and this concept has been explored and refined into several propositions over the years (Laakso, 2011). Acquiring and manipulating knowledge in real life is a bodily activity (Wilson, 2002) and cognitive processing involves the integration of information across both body and brain (Herbert \& Pollatos, 2012). Varela et al. (1974) proposed that an entity is a property of the whole and not just of its components. The whole is a series of continuous interactions between the brain and the environment in which it exists and which constrain its cognitive functioning. The body is not merely a set of physical properties but is an active agent that interacts with the environment and plays a role in cognition. The body and the environment are inseparable, they are intertwined. A central theme to all of this is embodiment, a term that invites to consider the body as an active agent that is not merely a passive vehicle of behaviour.

Embodied cognition works from the premise that perception and action are not simply an activity of the brain or central nervous system, but also include interaction with objects and sensory information from muscles, joints, and skin (L. B. Smith, 2005). The embodied cognition theories emphases how one needs a certain bodily state to prepare for a particular action (Matheson \& Barsalou, 2018; Herbert \& Pollatos, 2012). This is particularly true when it comes to motor control. Even simple actions such as opening a door require adequate bodily state such as being in equilibrium with gravity or having closed hands to push against the door handle. Another example of these relationships concerns how the motor system has been demonstrated to plays a key role in cognitive processes such as cognitive control (Koch et al., 2008), which is a critical process in everyday cognitive functioning (Niendam et al., 2012).

In light of the embodied cognition theories, it clearly seems that motor and cognitive functions are radically related and that commonalities should be taken into account for cognitive assessment. Yet, the clinical experiences of the first author widely contrast with this claim. Indeed, in typical neuropsychological screening, the motor side of cognition is rarely envisaged outside tests and scales that directly pertain to it 
(such as praxis performance). The present study is precisely conducted with this aim of developing new methods and tasks in VR for the evaluation of cognitive functioning by considering motor activity.

\subsection{A flankers task in virtual reality}

The flankers task is a computerized paradigm usually used to investigate cognitive control (Eriksen \& Eriksen, 1974; Fan et al., 2002). The task consists in the categorization of visual stimuli in a continuous sequence in which, the subject must usually categorize the left or right orientation of a centre stimuli (i.e., the target) by as fast as possible pressing of a button corresponding to the target orientation. Doing so necessitates to inhibit irrelevant parts of the stimuli (i.e., the flankers).

The task has already been used in a VR (Roberts et al., 2019) in which authors proposed a proof of concept by comparing the performances in VR environment and the usual laboratory situation conditions. They showed that performances were largely equivalent in both situations. However, Roberts and colleagues (2019) decided to propose a task very similar to the flankers task in the real world, for instance they faithfully reproduced the real world setting and a computer was reproduced in the virtual world. The flankers task is therefore an interesting candidate for implementation in VR and it might be interesting to manipulate the way the task is proposed in order to be able to track motor behaviour. The hypothesis that we develop in this introduction and that we aim to test is that such monitoring is likely to offer new insights into the cognitive profile.

More, concerning this task in particular, the correctness of the motor response depends on interhemispheric conflict (Soto et al., 2009; Verleger et al., 2009). Such conflict arises from the priming of inappropriate activation by the flankers, and of appropriate activation by the target. We make the hypothesis that the time course of this conflict and its resolution exceeds the time needed to press a key on a keyboard. To be more specific, tracing both whether this conflict exists and whether it is resolved could offer new insight into individual's cognitive control, and we propose that monitoring motor activity in a VR environment could provide such information.

If individuals are able to correct their behaviour when a motor response is already engaged, it could reflect their cognitive compensatory processes illustrating the resolving of the conflict created by the flankers task. Within this scope, we hypothesize firstly that the two main indicators of the flankers effect, namely increased duration time and increased amount of errors for incongruent flankers will be identified with a VR flankers task. Furthermore, we posit that a difference in motor activity should occur as a function of cognitive control processing and that this difference should be manifested predominantly for the motor response to incongruent stimuli.

\section{Method}

\subsection{Participants}

Seven French individuals were involved in this study (as described in Table 1). All participants were blind to the hypothesis and scope of the study. Prior to the study, they all gave informed consent and were briefed on what would be asked from them.

Table 1. Characteristics of the participants

\begin{tabular}{llll}
\hline Participant ID & age & sex & lateralization \\
\hline p1 & 24 & Male & Right \\
p2 & 30 & Female & Right \\
p3 & 30 & Male & Right \\
p4 & 31 & Male & Right
\end{tabular}


p5

p6

$\mathrm{p} 7$
Female

Female

Male
Left

Right

Right

\subsection{Experimental setup}

The environment was built using the Unity engine, a list of all assets used in this project is available in the supplementary material 1. The build of the environment (APK) is available in the supplementary material 2. The target device during development was the Oculus Quest 2 standalone headset; however, one participant performed the task using a Quest 1, which helped establish the compatibility of the environment with this headset. The positioning of the hands was deduced from the coordinates of the headset controllers.

A description of the environment setup is available in Figure 1a and $1 \mathrm{~b}$.

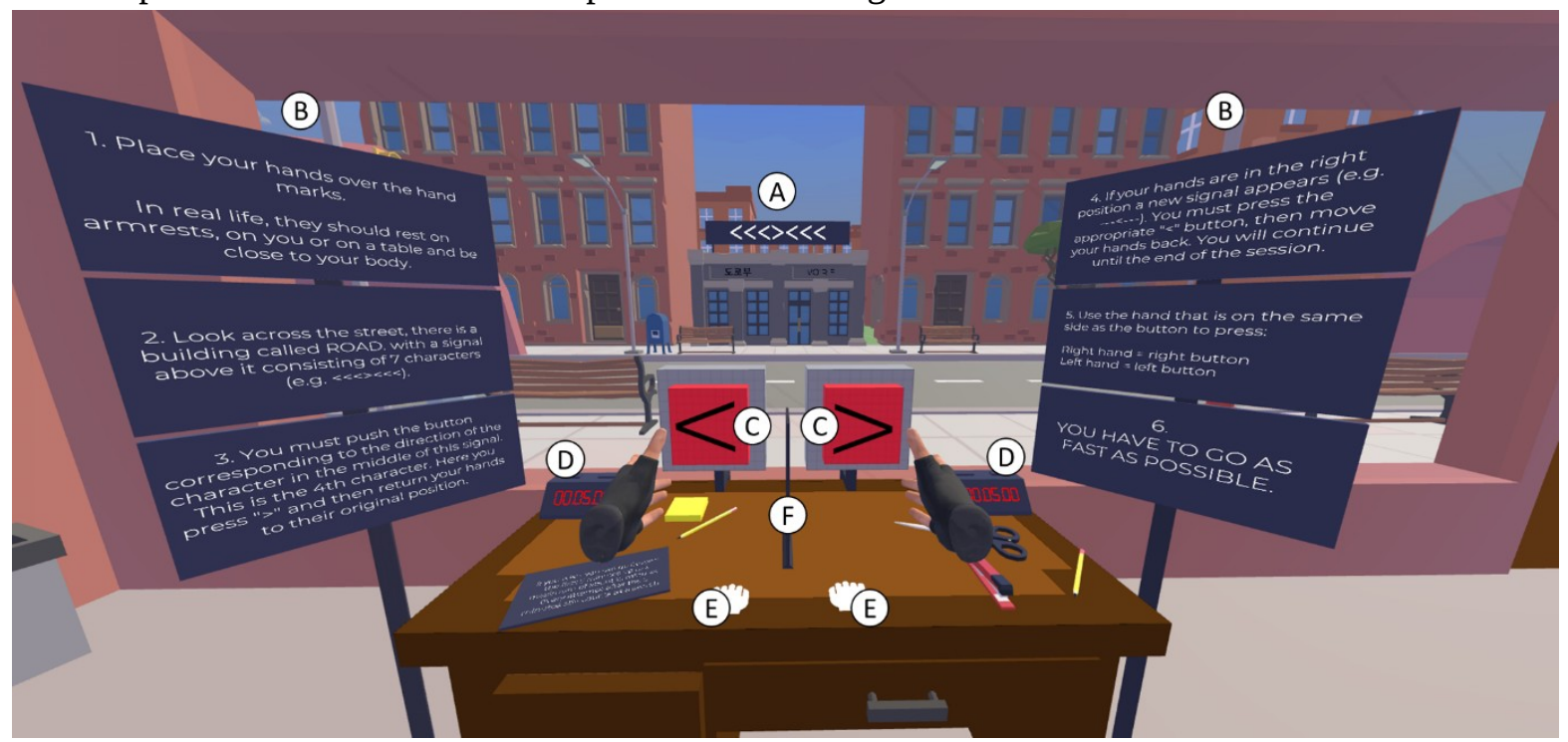

Figure 1a: Session setting. A: signal (central target and flankers), B: instruction panels, C: buttons to respond, D: timer to inform participants of the remaining time of their session, E: hand mark that turns black when the controllers are correctly positioned, $F$ : the blue triangle is not apparent during the session, it shows the centre of the initial positioning of the avatar (hand rig) of the participant, the middle panel is used as a nudging strategy to avoid crossing the hand to press the buttons.

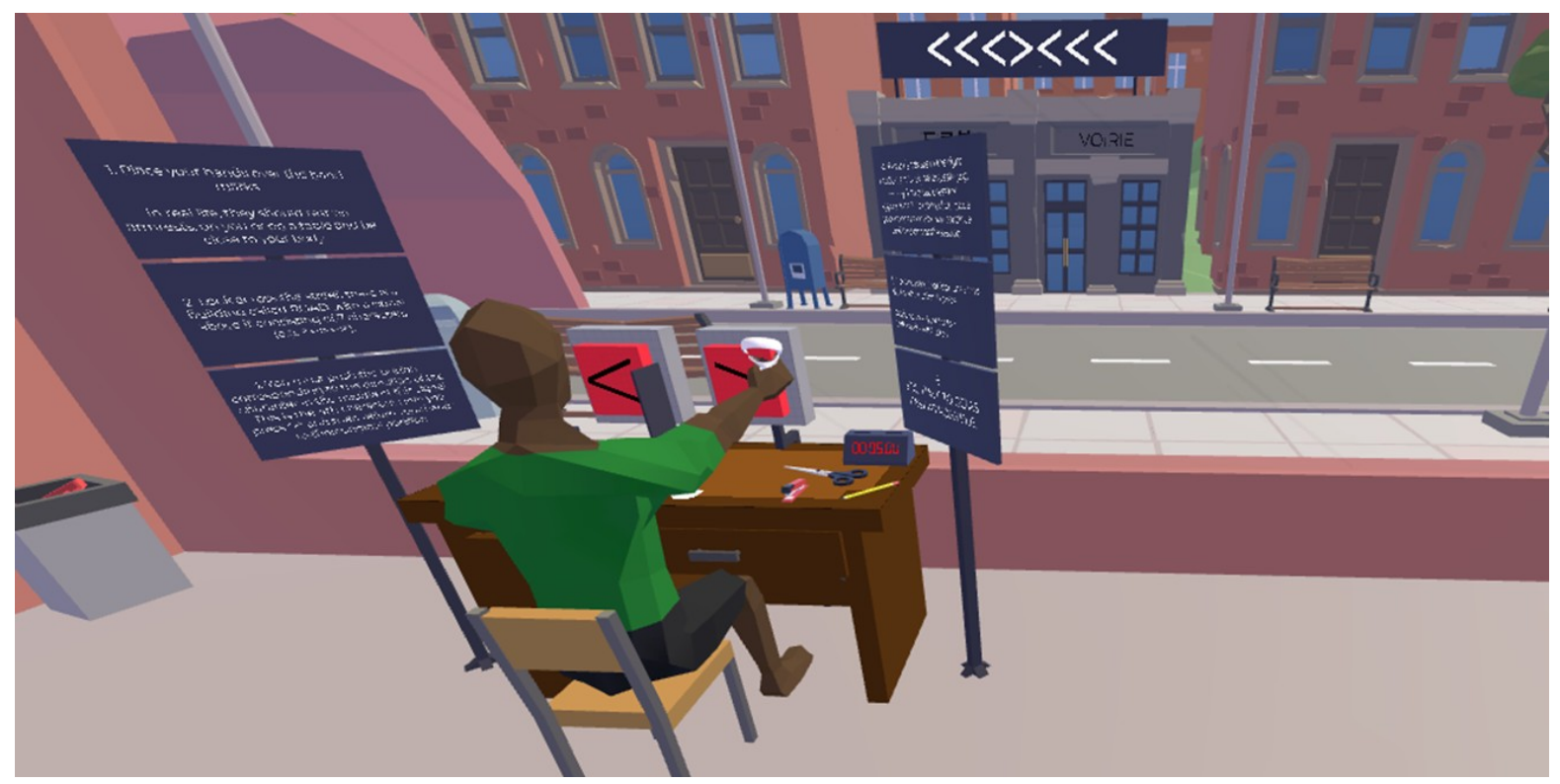


Figure 1b: There was no real counterpart to the virtual button, which means that the buttons were only displayed in the virtual world. In this image, the green avatar only serves to represent the user's position in the real world. Participants were asked to sit in front of a real desk or table and let their hand rest on it. If this first position was not comfortable, participants could also place their hand on the armrests of a chair.

\subsection{Experimental protocol}

Participants had to set up and launch the environment in their headset. Instructions were given orally or via a video prior to the run. Instruction were also shown in the environment written on six panels (translated from French): "1. Place your hands over the hand marks. In real life, they should REST on armrests, on you or on a table and be close to your body", "2. Look across the street, there is a building named 'ROAD' with a signal on top consisting of 7 characters (e.g. $<<<><<<$ )", "3. You must push the button corresponding to the direction of the character in the middle of this signal. This is the 4th character. Here you will press ' $>$ ' and then return your hands to their original position", "4. If your hands are in the right position a new signal appears (e.g. ---<---). You must press the appropriate '<' button, then move your hands back. You will continue until the end of the session", "5. Use the hand that is on the same side as the button to press: Right hand = right button and Left hand = left button", "6. YOU MUST GO AS FAST AS POSSIBLE".

A timer, located on the side of the virtual desk, was programmed to start after the first virtual button was pressed. It indicated that the session would last five minutes. Another instruction located on the virtual desk also indicated (translated from French): "If you wish, you can go beyond the first 5 minutes up to a maximum of about 15 minutes. Each attempt after the 5 minutes still counts for the research."

\section{Result}

Statistical tests were performed using the R language and Jamovi software. In accordance with our hypothesis, firstly, we compared the duration of trials based on incongruent (i.e., the signal showing $<<<><<<$ ), congruent (i.e., $>>>>>>>>$ ) and absent (i.e., --->---) flankers. Congruent and absent flankers will be referred as "other flankers" in this result section. Secondly, we calculated and compared the score depending on the button that was ultimately pressed. Thirdly, we tested if the motor responses of the contralateral hand (contralateral of the hand that ultimately pressed the button) was different depending on incongruent and other flankers. As a reminder, the signal is composed of two elements, on the one hand the target in the centre (fourth character) for which the individual must consider the orientation (right or left) and produce a pressure on the button and on the other hand the flankers that surround the target. The flankers can be congruent (pointing in the same direction as the target), incongruent (pointing in the opposite direction) or absent (horizontal line that does not point in a specific direction).

Considering the range of age, sex and lateralisation among our participants, tests were computed using an intra-subject design meaning that, for instance, trials of congruent flankers duration and correctness for participant 1 (p1) were only be compared to 11 incongruent flankers trials (and not to other participants).

The significance threshold for all testing was set at $p<.05$.

\subsection{Duration comparison}

Durations were computed by considering the delta between the time when the first frame in which the signal appeared and the time when the participant produced a push on the button. Only correct answers were considered in order to limit eventual spurious effects that may arise from incorrect processing. As the data did not meet the criteria for normality, we used the non-parametric Mann-Whitney U test for comparisons. In line with our hypothesis, the comparison of durations was directional (longer for the incongruent flankers than for the others). All comparison tables are available in the supplementary material. Seven comparisons 
were made, one per participant, and all were significant $(\mathrm{p}<.001)$. The mean duration of each participant's trials for the incongruent flankers and the others is displayed in Figure 2.

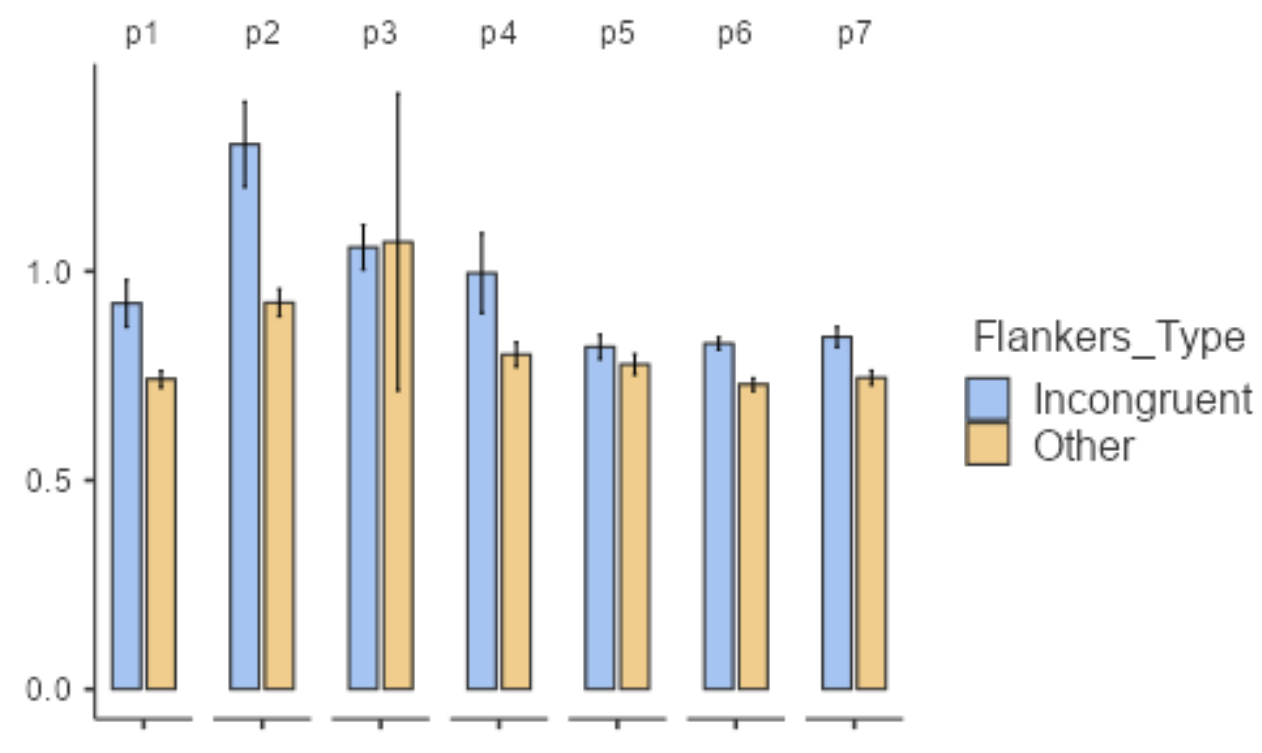

\section{Duration}

Figure 2: Trial duration (from signal onset to button press) for each participant considering incongruent $(<<<><<<$ or $>>><>>>)$ and other (--->--- or ---<--- or $>>>>>>$ or $<<<<<<<$ ) flankers. As a reminder, for each participant, comparison between incongruent and other flankers was significant with a p-value below .001..

\subsection{Score comparison}

All scores are depicted in Table 3. Scores were grouped depending on Flankers type (Congruent with the target, incongruent or absent) and compared using a Chi-Square Goodness of Fit Test, none were significant (results are available in supplementary material).

Table 3. Correct trials and total trials for each participant depending on the flankers and target type.

\begin{tabular}{llllllll}
\hline & $\mathrm{p} 1$ & $\mathrm{p} 2$ & $\mathrm{p} 3$ & $\mathrm{p} 4$ & $\mathrm{p} 5$ & $\mathrm{p} 6$ & $\mathrm{p} 7$ \\
\hline$>>>>>>>$ & $0 / 36$ & $0 / 21$ & $0 / 42$ & $0 / 31$ & $0 / 26$ & $0 / 38$ & $0 / 32$ \\
$<<<><<<$ & $0 / 36$ & $0 / 26$ & $\mathbf{2 / 3 7}$ & $0 / 25$ & $0 / 24$ & $0 / 37$ & $0 / 35$ \\
$---<---$ & $0 / 27$ & $0 / 22$ & $\mathbf{1 / 3 0}$ & $0 / 24$ & $0 / 27$ & $0 / 39$ & $0 / 30$ \\
$<<<<<<$ & $0 / 30$ & $0 / 30$ & $\mathbf{3 / 4 3}$ & $0 / 19$ & $0 / 35$ & $0 / 33$ & $0 / 23$ \\
$>>>>>>>$ & $0 / 36$ & $0 / 25$ & $0 / 36$ & $\mathbf{1 / 1 7}$ & $\mathbf{1 / 3 0}$ & $0 / 34$ & $\mathbf{3 / 4 0}$ \\
$--->---$ & $0 / 39$ & $0 / 29$ & $\mathbf{1 / 4 1}$ & $0 / 27$ & $0 / 33$ & $0 / 27$ & $0 / 49$ \\
\hline
\end{tabular}

Note. For readability, scores are represented by the number of incorrect trials/total trials; incorrect trials are in bold.

\subsection{Motor responses of the contralateral hand}

As the data did not mean the normality criteria, contralateral hand movements were compared between trials with incongruent, and other flankers using a Mann-Whitney U Test. In line with our hypothesis, the comparison of movement was directional (more movement for the incongruent flankers than for the others). Hand movements were calculated by summing all movements along the XYZ axes between the onset of the 
signal and the button press, with the scale of data being the metre. The contralateral hand was defined as the hand that did not press the button). The contralateral movement for each participant is represented in Figure 3.

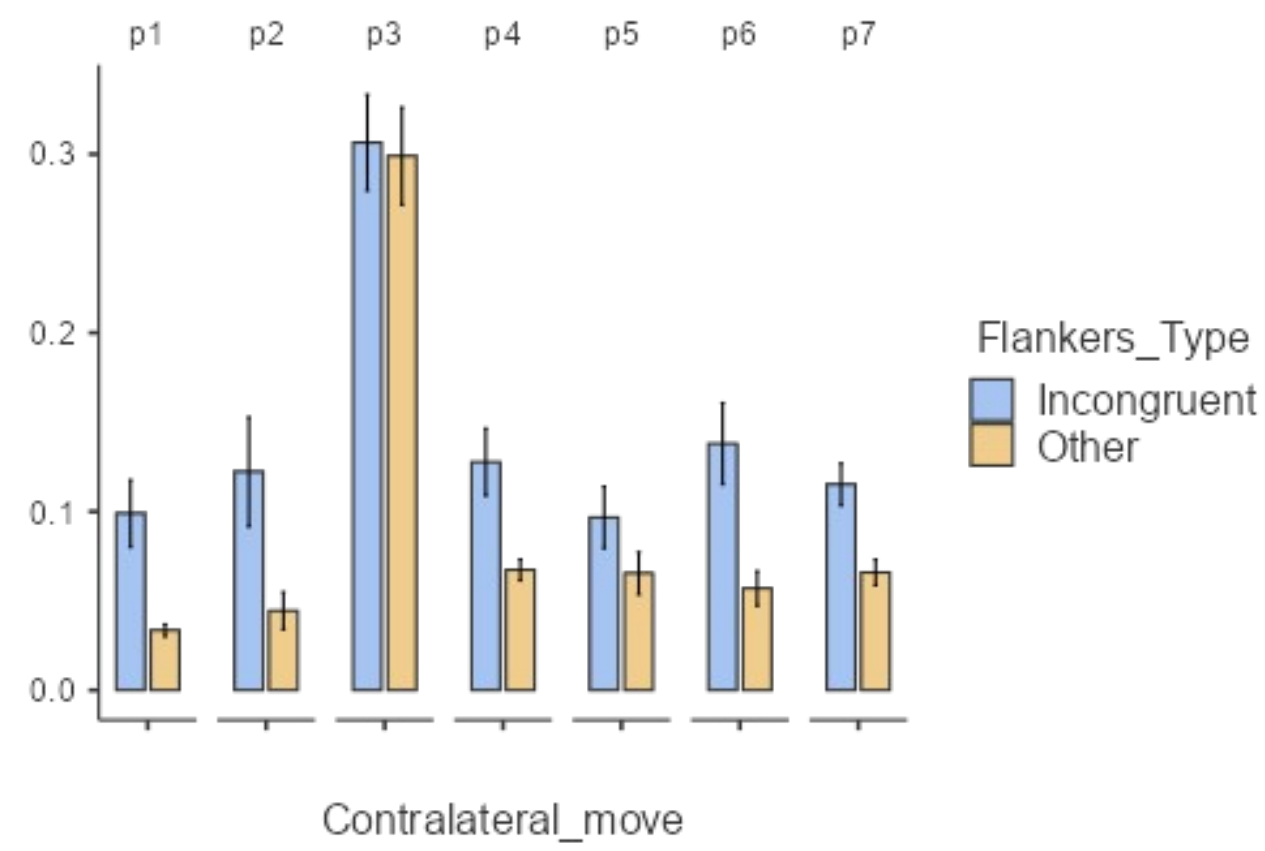

Figure 3: Contralateral hand moves (from signal onset to button press) for each participant considering incongruent $(<<<><<<$ or $>>><>>>)$ ) and other $(--->---$ or ------- or $>>>>>>>$ or $<<<<<<<)$ flankers. As a reminder, all comparisons between incongruent flankers and other flankers were significant with a p-value of less than 0.01, except for participant 3 where the comparison was not significant.

\section{Discussion}

In this study, we proposed to consider that the motor activity occurring in VR could be tracked and serves as a marker of cognitive functioning. In this context, we developed a virtual environment in which individuals performed a flankers task. Our objective was to evaluate and demonstrate, in an exploratory way, first, the usual results of the flankers task and, second, the existence of a new variable expressing the cognitive conflict through motor activity monitoring. We showed that the principle of the flankers task (showing a difference between congruent and incongruent trials) is respected in this environment and demonstrated how motor kinetics highlights this difference in a novel way.

The significant duration differences for all participants incongruent flankers trials and other flankers trials can be explained by two main propositions. The first proposal is that this difference reflects the cognitive cost of inhibiting interfering information while the second is that this difference reflects the cost of the process of selective attention specific to incongruent stimuli (Eriksen \& Eriksen, 1974; Kałamała et al., 2018; Pinner \& Cavanagh, 2017). Both interpretations are consistent with our observations.

Interestingly, the comparison of scores did not yield significant results, we interpret this as a demonstration that the initial motor response can be corrected by the cognitive system to better respond to the situation. Accordingly, the effect of incongruent flankers is not apparent in the score but is apparent in both trial duration and contralateral hand movements. Regarding the movements of the contralateral hand, the results show that they differ according to the type of flankers (incongruent or others). 
This influence on the contralateral motor side is invisible in the usual flankers task and is only apparent here by means of the use of VR. Indeed, the task of flankers is usually done with a computer and a keyboard. In this context, there is no space between the hand and the keyboard and this reflects on the lack of potential correction possible once the response is initiated. More conceptually, even with versions of flankers in which a distance can be imposed but movements are not tracked there would be an inability to inform incorrect mobilisations of the contralateral hand preceding a correct response. We propose that one of the main advantages of VR for such an investigation may lie in the fact that the kinematics of the hand are constantly and systematically monitored with the tracking technologies embedded in autonomous virtual reality headsets. How such tracking offers new insights into cognitive processing, through the analysis of movement, is the focus of this preliminary research. As we developed in the introduction, there is a strong ontological rationale for not considering movement as separate and independent from cognition. Thus, innovative methods of data collection and analysis of kinematic activity based on these technologies, such as the one we propose in this study, are welcome and necessary to better address cognitive functioning. Implementation of VR in clinical and experimental situations where cognitive tests are required has the potential to offer new insights into the functioning of participants, in line with several proposals made over the last decade (For a meta-analytic review see Negu et al., 2016).

This investigation was conducted as a preliminary research; future studies will define how these motor indicators should be analysed to reflect other aspects of cognition. This could, for example, help define whether the amount of time a person needs to change their behaviour is related to their cognitive control. A critical aspect of neuropsychological assessment of cognitive control and, more broadly, of executive functioning, is that it poorly reflects real-world performance. This discontinuity is a problem and VR has been proposed as a tool that could potentially overcome it (Jansari et al., 2014). The present study's results are aligned with this proposition.

The results for participant 3, are the only ones for which the comparison is not significant regarding contralateral movements. These results are intriguing and may suggest that some individuals have a different motor profile when faced with this flankers task. The results of p3, however, still show the cost of incongruent trials on the temporal aspect suggesting a possible independence of these two indicators. A more focused study on participants' backgrounds and a between-subjects comparison are needed to provide answers to these questions. The APK available in the supplementary material should facilitate such explorations.

This study was conducted using a widely used commercial stand-alone headset. An advantage is that it provides standardisation in terms of hardware, which is likely to facilitate standardisation of experimental conditions when experimenting from a distance (Mottelson et al., 2021). We suggest that a follow-up to this preliminary study could be done using the SideQuest software (Steed et al., 2021). Based on Steed et al. (2021), such unsupervised execution of our task could be done by implementing a more extensive tutorial, either within the application or on a dedicated web platform, and by monitoring the activity of individuals within the application. It is interesting to note that this monitoring is already at the heart of our approach.

In conclusion, this study illustrated the ease with which tracking a person's motor activity can be obtained in a VR environment. We were able to relate this new activity-provided performance indicator to the cognitive performance typically obtained in real life with this task. This new possibility should be studied in more detail to better situate how it could be useful as a new neuropsychological tool for monitoring cognitive status. In our opinion, this study was made possible by the recent development of VR technology. Standalone VR headsets allow ambulatory assessment while not restricting the individual's movement. The fact that they allow the assessment of high-frequency motor activity at relatively low cost is a relatively new situation that clinicians and researchers need to embrace in order to develop new tools for studying 
cognition. Embodied theories of cognition have largely emphasized the need for such motor assessments, and it is essential to continue exploring and proposing new uses and tasks for this technology in the future.

\section{Acknowledgements}

We would like to thank Pierre Maupin for his advice about the unity software and Julie Goubert, Roman Malo, Pierre Maupin, David and Laetitia Ribeiro and Nicolas and Pauline Villain for their help, during the conception pre-tests, in defining adequate testing parameters.

This work is part of the project "Executive Functions Testing in VR" funded by the Pays de la Loire French region through the West Creative Industries program.

\section{References}

Boyle, P. A., Cohen, R. A., Paul, R., Moser, D., \& Gordon, N. (2002). Cognitive and motor impairments predict functional declines in patients with vascular dementia. International Journal of Geriatric Psychiatry, 17(2), 164-169. fdoi.org/10.1002/gps.539

Eriksen, B. A., \& Eriksen, C. W. (1974). Effects of noise letters upon the identification of a target letter in a nonsearch task. Perception \& Psychophysics, 16(1), 143-149. doi:10.3758/BF03203267

Fan, J., McCandliss, B. D., Sommer, T., Raz, A., \& Posner, M. I. (2002). Testing the efficiency and independence of attentional networks. Journal of Cognitive Neuroscience. Journal of Cognitive Neuroscience, 14(3), 340-347.

Georgopoulos, A. P. (2000). Neural aspects of cognitive motor control. Current Opinion in Neurobiology, 10(2), 238-241. doi:10.1016/S0959-4388(00)00072-6

Gounden, Y., Hainselin, M., Cerrotti, F., \& Quaglino, V. (2017). Dynamic and Functional Approach to Human Memory in the Brain: A Clinical Neuropsychological Perspective. Frontiers in Psychology, 8, 688.

Herbert, B. M., \& Pollatos, O. (2012). The Body in the Mind: On the Relationship Between Interoception and Embodiment. Topics in Cognitive Science, 4(4), 692-704. doi:10.1111/j.1756-8765.2012.01189.x

Inzitari, M., Di Carlo, A., Baldereschi, M., Pracucci, G., Maggi, S., Gandolfo, C., Bonaiuto, S., Farchi, G., Scafato, E., Carbonin, P., \& Inzitari, D. (2006). Risk and predictors of motor-performance decline in a normally functioning population-based sample of elderly subjects: The Italian longitudinal study on aging. Journal of the American Geriatrics Society, 54(2), 318-324. doi:10.1111/j.15325415.2005.00584.x

Jansari, A. S., Devlin, A., Agnew, R., Akesson, K., Murphy, L., \& Leadbetter, T. (2014). Ecological assessment of executive functions: A new virtual reality paradigm. Brain Impairment, 15(2), 71-87. doi:10.1017/BrImp.2014.14

Jeannerod, M. (2006). Motor cognition: What actions tell the self (Issue 42). Oxford University Press.

Jensen, L., \& Konradsen, F. (2018). A review of the use of virtual reality head-mounted displays in education and training. Education and Information Technologies, 23(4), 1515-1529. doi:10.1007/s10639-0179676-0

Kałamała, P., Szewczyk, J., Senderecka, M., \& Wodniecka, Z. (2018). Flanker task with equiprobable congruent and incongruent conditions does not elicit the conflict N2. Psychophysiology, 55(2), 1-15. doi:10.1111/psyp.12980

Kan Yeung, A. W., Tosevska, A., Klager, E., Eibensteiner, F., Laxar, D., Stoyanov, J., Glisic, M., Zeiner, S., Kulnik, S. T., Crutzen, R., Kimberger, O., Kletecka-Pulker, M., Atanasov, A. G., \& Willschke, H. (2021). Virtual and augmented reality applications in medicine: Analysis of the scientific literature. Journal of Medical Internet Research, 23(2). doi:10.2196/25499

Koch, S., Holland, R. W., \& van Knippenberg, A. (2008). Regulating cognitive control through approachavoidance motor actions. Cognition, 109(1), 133-142. doi:10.1016/j.cognition.2008.07.014

Kourtesis, P., Collina, S., Doumas, L. A. A., \& MacPherson, S. E. (2021). Validation of the Virtual Reality Everyday Assessment Lab (VR-EAL): An Immersive Virtual Reality Neuropsychological Battery with Enhanced Ecological Validity. Journal of the International Neuropsychological Society, 27(2), 181196. doi:10.1017/S1355617720000764

La Corte, V., Sperduti, M., Abichou, K., \& Piolino, P. (2019). Episodic memory assessment and remediation in normal and pathological aging using virtual reality: A mini review. Frontiers in Psychology, 10(FEB), 1-6. doi:10.3389/fpsyg.2019.00173 
Laakso, A. (2011). Embodiment and development in cognitive science. Cognitie, Creier, Comportament/Cognition, Brain, Behavior, 15(4).

Liu, Y., Tan, W., Chen, C., Liu, C., Yang, J., \& Zhang, Y. (2019). A Review of the Application of Virtual Reality Technology in the Diagnosis and Treatment of Cognitive Impairment. Frontiers in Aging Neuroscience, 11(October), 1-5. doi:10.3389/fnagi.2019.00280

Matheson, H. E., \& Barsalou, L. W. (2018). Embodiment and Grounding in Cognitive Neuroscience. Stevens' Handbook of Experimental Psychology and Cognitive Neuroscience, 1-27. doi:10.1002/9781119170174.epcn310

Montero-Odasso, M., Speechley, M., Muir-Hunter, S. W., Sarquis-Adamson, Y., Sposato, L. A., Hachinski, V., Borrie, M., Wells, J., Black, A., Sejdić, E., Bherer, L., \& Chertkow, H. (2018). Motor and Cognitive Trajectories Before Dementia: Results from Gait and Brain Study. Journal of the American Geriatrics Society, 66(9), 1676-1683. doi:10.1111/jgs.15341

Mottelson, A., Petersen, G. B., Lilija, K., \& Makransky, G. (2021). Conducting Unsupervised Virtual Reality User Studies Online. Frontiers in Virtual Reality, 2(May), 1-12. doi:10.3389/frvir.2021.681482

Negu, A., Matu, S. A., Sava, F. A., \& David, D. (2016). Virtual reality measures in neuropsychological assessment: A meta-analytic review. Clinical Neuropsychologist, 30(2), 165-184. doi:10.1080/13854046.2016.1144793

Niendam, T. A., Laird, A. R., Ray, K. L., Dean, Y. M., Glahn, D. C., \& Carter, C. S. (2012). Meta-analytic evidence for a superordinate cognitive control network subserving diverse executive functions. Cognitive, Affective and Behavioral Neuroscience, 12(2), 241-268. doi:10.3758/s13415-011-0083-5

Parsons, T. D. (2015). Virtual reality for enhanced ecological validity and experimental control in the clinical, affective and social neurosciences. Frontiers in Human Neuroscience, 9(DEC), 1-19. doi:10.3389/fnhum.2015.00660

Pinheiro, P. A., Passos, T. D. E. R. O., da Silva Coqueiro, R., Fernandes, M. H., \& Barbosa, A. R. (2013). Motor performance of the elderly in northeast brazil: Differences with age and sex. Revista Da Escola de Enfermagem, 47(1), 125-133. doi:10.1590/S0080-62342013000100016

Pinner, J. F. L., \& Cavanagh, J. F. (2017). Frontal theta accounts for individual differences in the cost of conflict on decision making. Brain Research, 1672, 73-80. doi:10.1016/j.brainres.2017.07.026

Plancher, G., Tirard, A., Gyselinck, V., Nicolas, S., \& Piolino, P. (2012). Using virtual reality to characterize episodic memory profiles in amnestic mild cognitive impairment and Alzheimer's disease: Influence of active and passive encoding. Neuropsychologia, 50(5), 592-602. doi:10.1016/j.neuropsychologia.2011.12.013

Pulvermüller, F., Moseley, R. L., Egorova, N., Shebani, Z., \& Boulenger, V. (2014). Motor cognition-motor semantics: Action perception theory of cognition and communication. Neuropsychologia, 55(1), 71-84. doi:10.1016/j.neuropsychologia.2013.12.002

Ribeiro, N., Gounden, Y., \& Quaglino, V. (2020a). A full night’s sleep at home improves memory performance in an associative and relational learning task. Dreaming. doi:10.1037/drm0000130

Ribeiro, N., Gounden, Y., \& Quaglino, V. (2021). Enhancement of spatial memories at the associa- tive and relational levels after a full night of sleep and likelihood of dream incorporation. 14(1), 67-79. doi:10.11588/ijodr.2021.1.75882

Ribeiro, N., Sagnier, C., Quaglino, V., Gounden, Y., \& Loup-Escande, E. (2020b). Effect of a short rest period on associative and relational memory performance: A Virtual Reality study. International Journal of Virtual Reality, 20(1), 21-32. doi:10.20870/ijvr.2020.20.1.3186

Roberts, A. C., Yeap, Y. W., Seah, H. S., Chan, E., Soh, C. K., \& Christopoulos, G. I. (2019). Assessing the suitability of virtual reality for psychological testing. Psychological Assessment, 31(3), 318-328. doi:10.1037/pas0000663

Sagnier, C., Loup-Escande, É., \& Valléry, G. (2019). Technology acceptance of virtual reality: A review. Le Travail Humain, 82(3), 183-212.

Sagnier, C., Loup-Escande, É., \& Valléry, G. (2021). Virtual Reality: Definitions, Characteristics and Applications in the Workplace. Digital Transformations in the Challenge of Activity and Work: Understanding and Supporting Technological Changes, 3, 31-44.

Scarmeas, N., Albert, M., Brandt, J., Blacker, D., Hadjigeorgiou, G., Papadimitriou, A., Dubois, B., Sarazin, M., Wegesin, D., Marder, K., Bell, K., Honig, L., \& Stern, Y. (2005). Motor signs predict poor outcomes in Alzheimer disease. Neurology, 64(10), 1696-1703. doi:10.1212/01.WNL.0000162054.15428.E9

Simos, P. G., Kavroulakis, E., Maris, T., Papadaki, E., Boursianis, T., Kalaitzakis, G., \& Savaki, H. E. (2017). Neural foundations of overt and covert actions. NeuroImage, 152(November 2016), 482-496. 
doi:10.1016/j.neuroimage.2017.03.036

Smith, L. B. (2005). Cognition as a dynamic system: Principles from embodiment. Developmental Review, 25(3-4), 278-298. doi:10.1016/j.dr.2005.11.001

Smith, S. A. (2019). Virtual reality in episodic memory research: A review. Psychonomic Bulletin and Review, 26(4), 1213-1237. doi:10.3758/s13423-019-01605-w

Soto, D., Montoro, P. R., \& Humphreys, G. W. (2009). Transcranial magnetic stimulation of the primary motor cortex modulates response interference in a flanker task. Neuroscience Letters, 451(3), 261-265. doi:10.1016/j.neulet.2008.12.052

Steed, A., Archer, D., Congdon, B., Friston, S., Swapp, D., \& Thiel, F. J. (2021). Some Lessons Learned Running Virtual Reality Experiments Out of the Laboratory, 5-7. Retrieved from http://arxiv.org/abs/2104.05359

Varela, F. G., Maturana, H. R., \& Uribe, R. (1974). Autopoiesis: the organization of living systems, its characterization and a model. Biosystems, 5(4), 187-196.

Verleger, R., Kuniecki, M., Möller, F., Fritzmannova, M., \& Siebner, H. R. (2009). On how the motor cortices resolve an inter-hemispheric response conflict: An event-related EEG potential-guided TMS study of the flankers task. European Journal of Neuroscience, 30(2), 318-326. doi:10.1111/j.14609568.2009.06817.x

Wilson, M. (2002). Six views of embodied cognition. Psychonomic Bulletin \& Review, 9(4), 625-636. doi:10.3758/BF03196322 


\section{Supplementary 1 : Asset}

Asset used in this project:

POLYGON City - Low Poly 3D Art by Synty Studios

Simple Shop Interiors - Cartoon assets by Synty Studios

FREE Skybox Extended Shader by BOXOPHOBIC

Cartoon Low Poly City Pack Lite by JustCreate

Office Supplies Low Poly by Sten Ulfsson

VR Interaction Framework by Bearded Ninja Games

\section{Supplementary 2 : Score}

\section{Score comparison}

As a reminder only p3, p4, p5 and p7 made one or more error (see Table 2 in the manuscript). As such, only testing pertaining to these participants will be reproduced here. As previously mentioned, none of these comparisons yielded significant value.

\begin{tabular}{|c|c|c|c|c|c|c|c|c|}
\hline & Cont & enc & Table & & & & Tests & \\
\hline \multirow{6}{*}{ p3 } & \multicolumn{4}{|c|}{ V2 } & & \multirow[b]{2}{*}{ Value } & \multirow[b]{2}{*}{ df } & \multirow[b]{2}{*}{$\mathbf{p}$} \\
\hline & v1 & 0 & 1 & Total & & & & \\
\hline & Absent & 2 & 69 & 71 & \multirow{3}{*}{$\begin{array}{l}\chi^{2} \\
N\end{array}$} & \multirow{2}{*}{0.103} & \multirow{3}{*}{2} & \multirow{3}{*}{0.950} \\
\hline & Congruent & 3 & 82 & 85 & & & & \\
\hline & Incongruent & 2 & 71 & 73 & & 229 & & \\
\hline & Total & 7 & 222 & 229 & & & & \\
\hline \multirow{6}{*}{ p4 } & \multirow[b]{2}{*}{ v1 } & \multicolumn{2}{|c|}{ V2 } & \multirow[b]{2}{*}{ Total } & & \multirow{2}{*}{ Value } & \multirow[b]{2}{*}{ df } & \multirow{2}{*}{$\mathbf{p}$} \\
\hline & & 0 & 1 & & & & & \\
\hline & Absent & 0 & 51 & 51 & \multirow{3}{*}{$\begin{array}{l}\chi^{2} \\
N\end{array}$} & \multirow{3}{*}{$\begin{array}{r}2.42 \\
143\end{array}$} & \multirow{3}{*}{2} & \multirow{2}{*}{0.298} \\
\hline & Congruent & 0 & 50 & 50 & & & & \\
\hline & Incongruent & 1 & 41 & 42 & & & & \\
\hline & Total & 1 & 142 & 143 & & & & \\
\hline \multirow{6}{*}{ p5 } & \multirow[b]{2}{*}{ V1 } & \multicolumn{2}{|c|}{ V2 } & & & \multirow{2}{*}{ Value } & \multirow{2}{*}{$d f$} & \multirow{2}{*}{$\mathbf{p}$} \\
\hline & & 0 & 1 & Total & & & & \\
\hline & Absent & 0 & 60 & 60 & \multirow{3}{*}{$\begin{array}{l}\chi^{2} \\
N\end{array}$} & \multirow{3}{*}{$\begin{array}{r}2.25 \\
175\end{array}$} & \multirow{3}{*}{2} & \multirow{2}{*}{0.324} \\
\hline & Congruent & 0 & 61 & 61 & & & & \\
\hline & Incongruent & 1 & 53 & 54 & & & & \\
\hline & Total & 1 & 174 & 175 & & & & \\
\hline \multirow{3}{*}{ p7 } & & \multicolumn{2}{|c|}{ V2 } & \multirow[b]{2}{*}{ Total } & & Value & df & $\mathbf{p}$ \\
\hline & V1 & 0 & 1 & & $x^{2}$ & 5.44 & 2 & 0.066 \\
\hline & Absent & 0 & 79 & 79 & $\mathrm{~N}$ & 209 & & \\
\hline
\end{tabular}




\begin{tabular}{|l|llll|l|}
\hline Congruent & 0 & 55 & 55 \\
Incongruent & 3 & 72 & 75 \\
Total & 3 & 206 & 209 \\
\hline
\end{tabular}

3. Supplementary 3 : descriptive table

Descriptives

\begin{tabular}{|c|c|c|c|c|}
\hline & Flankers_Type & Participant_ID & Duration & Contralateral_move \\
\hline \multirow[t]{14}{*}{ N } & Incongruent & $\mathrm{p} 1$ & 72 & 72 \\
\hline & & p2 & 51 & 51 \\
\hline & & p3 & 71 & 71 \\
\hline & & $\mathrm{p} 4$ & 62 & 62 \\
\hline & & p5 & 55 & 55 \\
\hline & & p6 & 71 & 71 \\
\hline & & p7 & 72 & 72 \\
\hline & Other & p1 & 132 & 132 \\
\hline & & p2 & 102 & 102 \\
\hline & & p3 & 151 & 151 \\
\hline & & p4 & 133 & 133 \\
\hline & & p5 & 131 & 131 \\
\hline & & p6 & 137 & 137 \\
\hline & & p7 & 134 & 134 \\
\hline \multirow[t]{14}{*}{ Missing } & Incongruent & p1 & 0 & 0 \\
\hline & & p2 & 0 & 0 \\
\hline & & p3 & 0 & 0 \\
\hline & & p4 & 0 & 0 \\
\hline & & p5 & 0 & 0 \\
\hline & & p6 & 0 & 0 \\
\hline & & p7 & 0 & 0 \\
\hline & Other & $\mathrm{p} 1$ & 0 & 0 \\
\hline & & p2 & 0 & 0 \\
\hline & & p3 & 0 & 0 \\
\hline & & p4 & 0 & 0 \\
\hline & & p5 & 0 & 0 \\
\hline & & p6 & 0 & 0 \\
\hline & & p7 & 0 & 0 \\
\hline \multirow[t]{5}{*}{ Mean } & Incongruent & p1 & 0.923 & 0.0989 \\
\hline & & p2 & 1.30 & 0.122 \\
\hline & & p3 & 1.06 & 0.306 \\
\hline & & p4 & 0.996 & 0.128 \\
\hline & & p5 & 0.819 & 0.0967 \\
\hline
\end{tabular}




\begin{tabular}{|c|c|c|c|c|}
\hline & Flankers_Type & Participant_ID & Duration & Contralateral_move \\
\hline & & p6 & 0.827 & 0.138 \\
\hline & & p7 & 0.843 & 0.115 \\
\hline & Other & p1 & 0.742 & 0.0335 \\
\hline & & p2 & 0.925 & 0.0444 \\
\hline & & p3 & 1.07 & 0.299 \\
\hline & & p4 & 0.801 & 0.0673 \\
\hline & & p5 & 0.777 & 0.0654 \\
\hline & & p6 & 0.729 & 0.0569 \\
\hline & & p7 & 0.745 & 0.0659 \\
\hline \multirow[t]{14}{*}{ Median } & Incongruent & p1 & 0.752 & 0.0345 \\
\hline & & p2 & 1.03 & 0.0366 \\
\hline & & p3 & 0.913 & 0.252 \\
\hline & & p4 & 0.774 & 0.0654 \\
\hline & & p5 & 0.758 & 0.0322 \\
\hline & & p6 & 0.813 & 0.0442 \\
\hline & & p7 & 0.777 & 0.0911 \\
\hline & Other & p1 & 0.657 & 0.0233 \\
\hline & & p2 & 0.815 & 0.0260 \\
\hline & & p3 & 0.647 & 0.261 \\
\hline & & p4 & 0.702 & 0.0404 \\
\hline & & p5 & 0.679 & 0.0226 \\
\hline & & p6 & 0.691 & 0.0263 \\
\hline & & p7 & 0.678 & 0.0330 \\
\hline \multirow[t]{14}{*}{ Standard deviation } & Incongruent & $\mathrm{p} 1$ & 0.475 & 0.159 \\
\hline & & p2 & 0.728 & 0.218 \\
\hline & & p3 & 0.451 & 0.226 \\
\hline & & p4 & 0.750 & 0.148 \\
\hline & & p5 & 0.214 & 0.128 \\
\hline & & p6 & 0.124 & 0.192 \\
\hline & & p7 & 0.204 & 0.0998 \\
\hline & Other & $\mathrm{p} 1$ & 0.230 & 0.0386 \\
\hline & & p2 & 0.329 & 0.105 \\
\hline & & p3 & 4.36 & 0.335 \\
\hline & & p4 & 0.335 & 0.0676 \\
\hline & & p5 & 0.283 & 0.135 \\
\hline & & p6 & 0.178 & 0.113 \\
\hline & & p7 & 0.196 & 0.0833 \\
\hline \multirow[t]{3}{*}{ Minimum } & Incongruent & $\mathrm{p} 1$ & 0.613 & 0.0131 \\
\hline & & p2 & 0.682 & 0.00355 \\
\hline & & p3 & 0.557 & 0.117 \\
\hline
\end{tabular}




\begin{tabular}{|c|c|c|c|c|}
\hline & Flankers_Type & Participant_ID & Duration & Contralateral_move \\
\hline & & $\mathrm{p} 4$ & 0.580 & 0.0153 \\
\hline & & p5 & 0.624 & 0.0119 \\
\hline & & p6 & 0.546 & 0.00948 \\
\hline & & p7 & 0.634 & 0.0136 \\
\hline & Other & p1 & 0.523 & 0.00830 \\
\hline & & p2 & 0.557 & 0.00320 \\
\hline & & p3 & 0.513 & 0.0581 \\
\hline & & $\mathrm{p} 4$ & 0.523 & 0.0167 \\
\hline & & p5 & 0.512 & 0.01000 \\
\hline & & p6 & 0.468 & 0.00934 \\
\hline & & p7 & 0.567 & 0.00780 \\
\hline \multirow[t]{14}{*}{ Maximum } & Incongruent & $\mathrm{p} 1$ & 3.93 & 0.750 \\
\hline & & p2 & 4.50 & 0.926 \\
\hline & & p3 & 3.20 & 1.60 \\
\hline & & p4 & 5.96 & 0.657 \\
\hline & & p5 & 1.78 & 0.500 \\
\hline & & p6 & 1.50 & 0.911 \\
\hline & & p7 & 1.56 & 0.515 \\
\hline & Other & $\mathrm{p} 1$ & 1.78 & 0.405 \\
\hline & & p2 & 2.59 & 1.02 \\
\hline & & p3 & 54.3 & 4.16 \\
\hline & & $\mathrm{p} 4$ & 2.71 & 0.486 \\
\hline & & p5 & 2.39 & 0.941 \\
\hline & & p6 & 1.73 & 0.740 \\
\hline & & p7 & 1.61 & 0.559 \\
\hline
\end{tabular}

\section{Supplementary 4 : comparison}

p1

Independent Samples T-Test

\begin{tabular}{llcclc}
\hline & & Statistic & p & & Effect Size \\
\hline Contralateral_move & Mann-Whitney U & 2936 & $<.001$ & Rank biserial correlation & 0.382 \\
Duration & Mann-Whitney U & 2613 & $<.001$ & Rank biserial correlation & 0.450 \\
\hline
\end{tabular}

Note. $H_{a} \mu$ Incongruent $>\mu$ Other 
p2

Independent Samples T-Test

\begin{tabular}{llcclc}
\hline & & Statistic & p & & Effect Size \\
\hline Contralateral_move & Mann-Whitney U & 1877 & 0.003 & Rank biserial correlation & 0.278 \\
Duration & Mann-Whitney U & 1358 & $<.001$ & Rank biserial correlation & 0.478 \\
\hline
\end{tabular}

Note. $H_{a} \mu_{\text {Incongruent }}>\mu_{\text {Other }}$

p3

Independent Samples T-Test

\begin{tabular}{llcclc}
\hline & & Statistic & p & & Effect Size \\
\hline Contralateral_move & Mann-Whitney U & 5229 & 0.616 & Rank biserial correlation & 0.0245 \\
Duration & Mann-Whitney U & 1883 & $<.001$ & Rank biserial correlation & 0.6488 \\
\hline
\end{tabular}

Note. $\mathrm{H}_{\mathrm{a}} \mu$ Incongruent $>\mu$ Other

p4

Independent Samples T-Test

\begin{tabular}{llcccc}
\hline & Statistic & p & & Effect Size \\
\hline Contralateral_move & Mann-Whitney U & 2844 & $<.001$ & Rank biserial correlation & 0.310 \\
Duration & Mann-Whitney U & 2651 & $<.001$ & Rank biserial correlation & 0.357 \\
\hline
\end{tabular}

Note. $H_{a} \mu_{\text {Incongruent }}>\mu_{\text {Other }}$

p5

Independent Samples T-Test

\begin{tabular}{llcclc}
\hline & & Statistic & p & & Effect Size \\
\hline Contralateral_move & Mann-Whitney U & 2717 & 0.004 & Rank biserial correlation & 0.246 \\
Duration & Mann-Whitney U & 2205 & $<.001$ & Rank biserial correlation & 0.388 \\
\hline
\end{tabular}

Note. $\mathrm{H}_{\mathrm{a}} \mu_{\text {Incongruent }}>\mu_{\text {Other }}$

p6 
Independent Samples T-Test

\begin{tabular}{llcccc}
\hline & Statistic & p & & Effect Size \\
\hline Contralateral_move & Mann-Whitney U & 2545 & $<.001$ & Rank biserial correlation & 0.477 \\
Duration & Mann-Whitney U & 1936 & $<.001$ & Rank biserial correlation & 0.602 \\
\hline
\end{tabular}

Note. $H_{a} \mu$ Incongruent $>\mu$ Other

p7

Independent Samples T-Test

\begin{tabular}{llcclc}
\hline & & Statistic & p & & Effect Size \\
\hline Contralateral_move & Mann-Whitney U & 2654 & $<.001$ & Rank biserial correlation & 0.450 \\
Duration & Mann-Whitney U & 2375 & $<.001$ & Rank biserial correlation & 0.508 \\
\hline
\end{tabular}

Note. $\mathrm{H}_{\mathrm{a}} \mu_{\text {Incongruent }}>\mu_{\text {Other }}$ 